\title{
Modelling and optimization studies on decolorization of brilliant green dye using integrated nanofiltration and photocatalysis
}

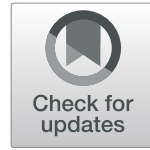

\author{
Naresh Yadav Donkadokula ${ }^{1,2^{*}}$, Anand Kishore Kola ${ }^{1}$ and Devendra Saroj ${ }^{2}$
}

\begin{abstract}
The current work explores the treatment of dye wastewater using the combination of photocatalysis and ceramic nanofiltration process. Commercial ceramic membrane and titanium dioxide $\left(\mathrm{TiO}_{2}\right)$ photocatalyst were used in this study to investigate the removal of Brilliant Green (BG) dye from the synthetic dye wastewater solution. The effect of various operating parameters on dye decolorization and total organic carbon removal were investigated. The operating parameters ( $\mathrm{pH}$, catalyst loading and time duration) were optimized using an experimental design model namely Response Surface Methodology (RSM). The use of experimental design by RSM resulted in the improvement of dye decolorization at optimum conditions. In addition to these operating parameters, the trend of initial dye concentration and the influence of catalyst loading on permeate flux was also studied. Around $99 \%$ of decolorization was obtained by the hybrid system at $500 \mathrm{mg} \mathrm{L}^{-1}$ of dye concentration, $1 \mathrm{~g} \mathrm{~L}^{-1}$ of $\mathrm{TiO}_{2}$ dosage, $\mathrm{pH}$ of 4.2 and $90 \mathrm{~min}$. The integrated system i.e. photocatalytic reactor with nanofiltration membrane has shown complete removal of BG dye compared to individual systems. From the present study, it can be concluded that this integrated system is one of the efficient methods for dye treatment.
\end{abstract}

Keywords: Dye degradation, Photocatalysis, Ceramic nanofiltration, Hybrid system, RSM

\section{Introduction}

Dyes have many applications in different industries on a large scale. At present, many industries such as paper, textile, food, cosmetic, pharmaceutical and leather consume a huge amount of dyes. Among the aforementioned industries, the dye usage quantity of the textile industry is approximately two-thirds of the total dyestuff available in the market [1]. Similarly, a textile industry consumes the bulk quantity of water for wet processing of textiles as well as for dyeing the cloths. The dyes are visible and are unpleasant even if they are in very small quantity. Dye effluents are more poisonous, mutagenic, and carcinogenic to several microbiological and aquatic lives. About $70 \%$ of the dyes are azo types which are mostly recalcitrant in nature and the

\footnotetext{
*Correspondence: d.nareshyadav1989@gmail.com

'Department of Chemical Engineering, National Institute of Technology Warangal, Warangal 506004, India

${ }^{2}$ Department of Civil and Environmental Engineering, University of Surrey, Guildford GU2 7XH, UK
}

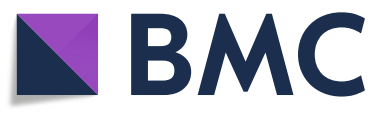

( ) The Author(s). 2020 Open Access This article is licensed under a Creative Commons Attribution 4.0 International License, which permits use, sharing, adaptation, distribution and reproduction in any medium or format, as long as you give

appropriate credit to the original author(s) and the source, provide a link to the Creative Commons licence, and indicate if changes were made. The images or other third party material in this article are included in the article's Creative Commons licence, unless indicated otherwise in a credit line to the material. If material is not included in the article's Creative Commons licence and your intended use is not permitted by statutory regulation or exceeds the permitted use, you will need to obtain permission directly from the copyright holder. To view a copy of this licence, visit http://creativecommons.org/licenses/by/4.0/. presence of azo dyes in wastewater leads to complications in treatment through biological methods [2]. In most of the textile industries azo dyes are utilized in a higher quantity $(60-70 \%)[3,4]$. Aromatic amines (AAs) are released as a result of the bacterial, systemic and dermal biotransformation of azo dyes $[5,6]$. The uninterrupted subjugation of skin to AAs leads to the inhalation exposure on a greater level and to the azo dye synthesis, where AAs are used as intermediates. The AA noxiousness confides in the amino group metabolic activation that produces the hydroxylamine intermediate which is familiar for protein and DNA mutilation. The European Union has banned the utilization of 22 azo dyes by the textile industries (Annex XVII of the REACH regulation; No. 1907/2006). All the banned azo dye are carcinogenic and releases AAs. The ordinance brought by the Switzerland government opposes human contact with azo dyes (SR 817.023.41) [7]. The banned 22 azo dyes were divided into different categories. Out of this, 8 were assigned 
to class A1 or A2 and 14 were allocated to category I and II $[3,7]$. Bruschweiler et al. [3] worked on the removal of noxious AAs from the azo dyes. According to the European Union's Annex XVII of REACH, out of 896 azo dyes only 426 are capable of producing the 22 controlled AAs and the remaining dyes can be categorized as nonregulated AAs. This study has taken the references from the European Commission Regulation 552/2009/EC which has banned the azo dyes containing AAs. With a maximum utility of $30 \mathrm{mg} \mathrm{kg}^{-1}$ textile, two AAs such as 4aminoazobenzene and $o$-anisidine were also prohibited along with those of 22 AAs. In this research work, from various textile industries of Switzerland, about 153 samples were collected and examined to identify 22 AAs. The 8 non-regulated noxious AAs were noticed from $17 \%$ of random samples. Hence this study has observed a regulatory gap between the Swiss regulation and REACH regulation, Annex XVII and hence this study suggests to fill this gap in a systematic and consistent manner.

Currently various wastewater treatment methods are in existence and most of the researchers are working on advanced oxidation processes (AOPs). Few researchers have been working on the integration of these AOPs with the existing conventional treatment techniques. Till date, the research on photocatalysis (PC) has been to explore the photocatalytic based AOPs, which attain more attention due to the mode in which they treated the dye wastewater. Also few studies have reportedly been on the separation of titanium dioxide $\left(\mathrm{TiO}_{2}\right)$ or other photocatalysts reusability by adopting coagulation and membrane separation $[3,4]$. In the coagulation method, photocatalysts were flocculated and settled down quickly, but the recovery of photocatalysts needs further treatment technique before it is reused/recycled. Due to the drawbacks of the coagulation, nanofiltration attracted as an emerging technique for the recovery of valuable compounds. Membrane separation not only involves the separation of suspended photocatalyst, but it also aids in the separation of dissolved organic as well as suspended organic/particulate matter from the effluent [8]. Therefore, membrane separation can be used to resolve the drawback/challenges associated with the coagulation. Moreover, the combination of PC with nanofiltration (NF) facilitates the stability of the membrane performance and mineralize various ranges of organic pollutants that are responsible for membrane fouling [9].

Mozia [10] have investigated the breakdown of toxic organic compounds in the presence of photocatalytic membrane reactor using immobilized $\mathrm{TiO}_{2}$ particles onto the surface of polymeric membranes and their investigations have shown that ultraviolet (UV) irradiation slightly damaged the polymeric membranes. Some investigations explored that the damage of polymer membranes could be due to the hydroxyl radical generation during UV irradiation [11-15]. Ceramic membranes are found to be an alternative to polymer membranes. It also possesses extraordinary characteristics like physical, mechanical, lower cleaning frequency, thermal stability, longer lifetime and chemical resistance [9-11]. Studies on the coupling of two technologies (ceramic membranes and AOPs) have shown the unusual and distinctive opportunity for water treatment. Enhanced filtration and the significant reduction in fouling of membrane can be achieved by the combination of ceramic membranes with various AOPs such as PC and ozonation. Generally, conventional filtration or coagulation cannot eliminate dissolved salts and organic compounds from wastewaters. This problem has been resolved by combining a few pre-treatment processes like $\mathrm{PC}$, coagulation and ozonation before the membrane filtration. Combining the PC or ozonation with the membrane filtration shows oxidation and segregation of organic pollutants [13, 14]. However, we found that no study so far has reported about the proposed hybrid system (combination of PC and NF) for Brilliant Green (BG) dye treatment.

As most of the water/wastewater treatment operations involve in multivariables and optimizing them with the traditional techniques would take more time and are unsubstantial [16]. Hence, such issues could be overcome through the novel experimental design models like Response Surface Methodology (RSM). The RSM is one of the broadly used mathematical methods for optimizing the operating parameters. It has several advantages and it is being used in several industries for the optimization of various experimental factors. It is flexible, efficient, reliable, energy and time-saving. In the current study, RSM has been used for the optimization of the operating factors such as catalyst loading, $\mathrm{pH}$ and time. Experiments were performed with the optimized factors developed by the RSM and observed magnificent results.

The core idea of this research is to investigate the ability of the proposed hybrid process for the treatment of BG dye wastewater. The effect of $\mathrm{TiO}_{2}$ concentration on the permeate flux and the effect of various operating conditions on permeate flux and decolorization was evaluated.

\section{Materials and methods \\ Materials}

The catalyst $\mathrm{TiO}_{2}$ (Degussa P25) and BG dye were purchased from M/s Sisco Research Laboratories Pvt. Ltd. Maharashtra, India. $\mathrm{NaOH}$ and sulfuric acids (98\%) were acquired from M/s SD Fine Chemicals Ltd., Mumbai, India. Analytical grade chemicals were used in this experimental work.

\section{Methodology}

PC combined with ceramic NF system is shown in Fig. 1. The system consists of $10 \mathrm{~L}$ feed tank outfitted with a 250 W UV light ( $365 \mathrm{~nm}$ maximum emission), low-pressure mercury vapor lamp (maximum emission at $365 \mathrm{~nm}$ ). This UV lamp has a double jacket around for the continuous water circulation during the experiment. It was mounted 


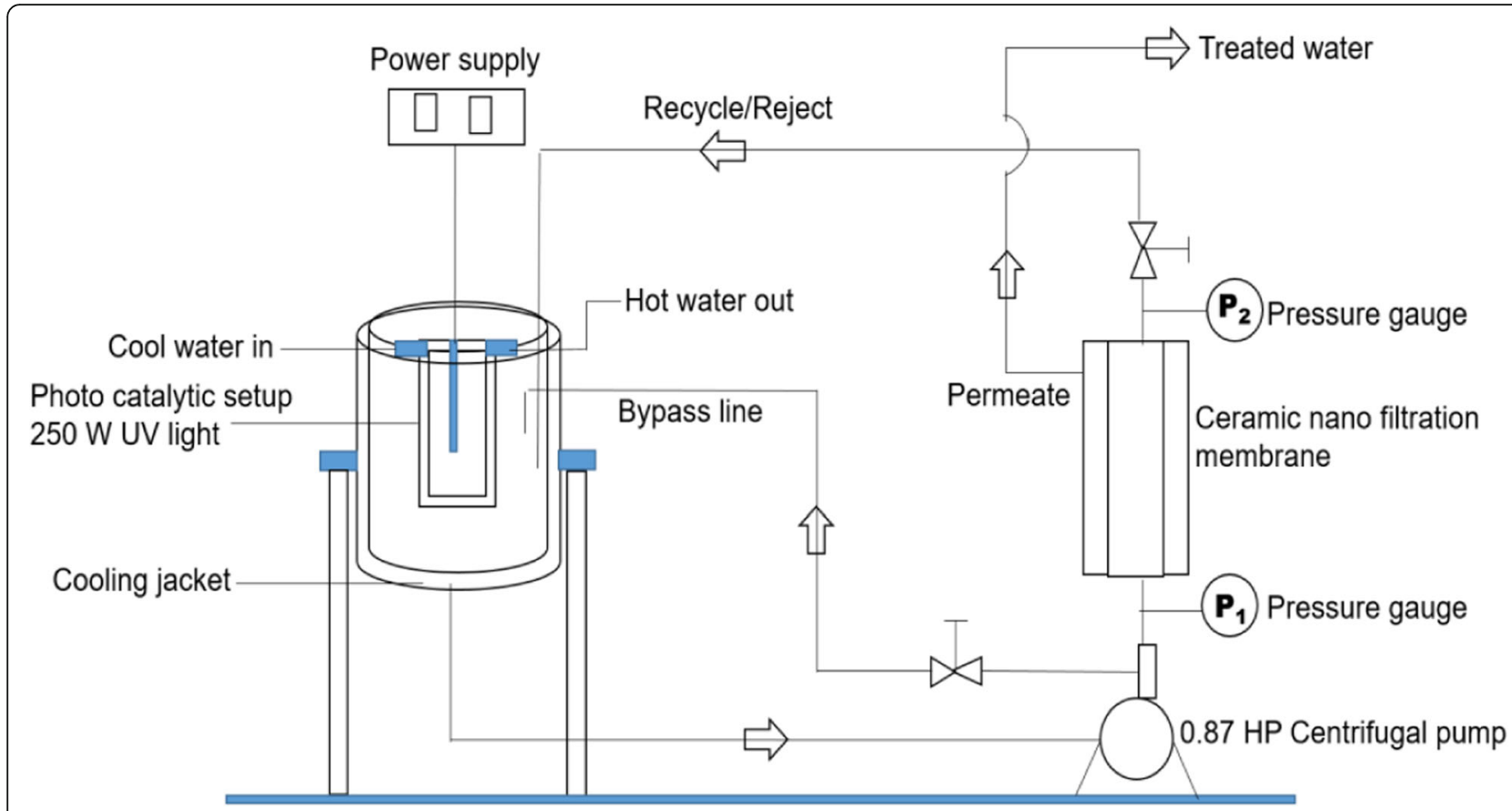

Fig. 1 Experimental layout of the integrated system

at the centre from the top side of the feed tank. Stainless steel (SS-316) was used in making the Photocatalytic reactor. Similar to the UV lamp, the feed tank also has a double jacket for the continuous supply of water to uphold the reactor temperature. The feed was pumped into the filtration membrane using $0.63 \mathrm{~kW}$ centrifugal pump.

The treated water was collected from the permeate for the analysis and the remaining water was sent back to the feed tank through retentate. This continuous circulation has helped in maintaining the $\mathrm{TiO}_{2}$ particles in suspended form. The commercial ceramic membrane module "Ceram INSIDE" was procured from M/s TAMI Industries. $\mathrm{TiO}_{2}$ active layer was used to coat the commercial ceramic membrane modules. In this experimental setup, the two individual systems ( $\mathrm{PC}$ and ceramic NF) were fixed at two different points and connected using connectors (Fig. 1). Photocatalytic activity takes place only in the feed tank. Though the ceramic membrane was coated with $\mathrm{TiO}_{2}$, there is no chance of light passage on to the membrane surface as it was thoroughly covered. Hence no photocatalytic activity took place on the surface of the ceramic membrane. Table 1 explains the technical specifications of the investigational modules utilized in this research work. To retain the appropriate flow rates and pressures in the system, pressure gauges, control valves and rotameters were kept at certain points. The removal of dye and organic pollutant in the integrated system enhances on sending the permeate and retentate back to the feed tank. The stock solution was prepared for $5 \mathrm{~L}$ at $500 \mathrm{mg} \mathrm{L}^{-1}$ of dye concentration in a container. After thorough mixing, the solution was transferred into the feed tank. High pressures $(400 \mathrm{kPa})$ were used in pumping the dye solution through the ceramic membrane. The solution present in the feed tank was pumped into the NF system by employing $0.63 \mathrm{~kW}$ centrifugal pumps. By regulating the control valves, the required pressure and flow rate to the vent of the membrane were retained. To control the inlet pressure an elude line was also utilized in addition to the control valve.

$P C$

Individual experiments were performed by employing PC at optimum operating conditions of catalyst loading $1 \mathrm{~g} \mathrm{~L}^{-1}, \mathrm{pH} 4.2$ and time $90 \mathrm{~min}$.

Table 1 Technical parameters of the experimental module

\begin{tabular}{ll}
\hline Parameter & Semi pilot installation \\
\hline Configuration & Tubular \\
Membrane material & Zirconium oxide $\left(\mathrm{ZrO}_{2}\right)$ \\
Effective surface area, $\mathrm{m}^{2}$ & 0.3 \\
Membrane pore size, $\mathrm{nm}$ & 2 \\
Number of Channels & 3 \\
Internal channel diameter, $\mathrm{mm}$ & 3.5 \\
External membrane diameter, $\mathrm{mm}$ & 10 \\
Membrane length, mm & 600 \\
\hline
\end{tabular}


NF

Individual experiments were performed by employing $\mathrm{NF}$ at optimum operating conditions of catalyst loading $1 \mathrm{~g} \mathrm{~L}^{-1}, \mathrm{pH} 4.2$ and time $90 \mathrm{~min}$.

\section{Combined system}

Experiments were performed by integrating $\mathrm{PC}$ and $\mathrm{NF}$ at optimum operating conditions of catalyst loading $1 \mathrm{~g}$ $\mathrm{L}^{-1}, \mathrm{pH} 4.2$ and time $90 \mathrm{~min}$.

The percentage rejection of dye by the NF unit was determined by using below equation.

$$
\text { Dye rejection }(\%)=\frac{C_{r}-C_{p}}{C_{r}} * 100
$$

where, $C_{r}=$ concentration of dye $\left(\mathrm{g} \mathrm{m}^{-3}\right)$ in retentate and $C_{p}=$ concentration of dye $\left(\mathrm{g} \mathrm{m}^{-3}\right)$ in permeate.

\section{Analytical method}

The UV-Vis Spectrophotometer 300 model supplied by $\mathrm{M} / \mathrm{s}$ Thermo Scientifics, England was used to check the UV absorbance. And it is known that the maximum absorbance of BG dye is $623 \mathrm{~nm}$ [17]. The standard calibration chart prepared for BG dye was used further to determine the concentration of dye. The total organic carbon (TOC) present in the feed, as well as the permeate, was analyzed using TOC analyzer (TOC ICPN analyzer, Shimadzu, Japan).

\section{Optimization of operating parameters}

The RSM is one of the best experimental design models that describe the appraisal of various operating variables' interactivity with the response variables. Hence, it is the combination of several mathematical and statistical methods to enhance the efficiency of operation.

In this work, the Central Composite Design (CCD) technique was employed to enhance the BG dye decolorization by optimizing the initial operating parameters. CCD, $2^{3}$ full factorial design was used to optimize the operating parameters (Catalyst loading, $\mathrm{pH}$ and time) influencing the dye decolorization [18]. The factors, their ranges and the response are mentioned in Table 2. Design-Expert software of version 7.0.0 was used to design the model.

Table 2 CCD matrix

\begin{tabular}{lll}
\hline Factor & Range & Response (R1) \\
\hline Catalyst loading (A) & $0.7-1.2 \mathrm{~g} \mathrm{~L}^{-1}$ & \% BG dye decolorization \\
$\mathrm{pH}(\mathrm{B})$ & $2-6$ & \\
Time (C) & $80-100 \mathrm{~min}$ & \\
\hline
\end{tabular}

\section{Results and discussion}

\section{Effect of catalyst loading}

The impact of $\mathrm{TiO}_{2}$ photocatalyst on the breakdown of BG dye has been studied in this process.

Different loadings over the range of $0.2-1.2 \mathrm{~g} \mathrm{~L}^{-1}$ of $\mathrm{TiO}_{2}$ catalyst were used to study the degradation performance of $\mathrm{TiO}_{2}$ in the hybrid system (PC coupled with NF). $500 \mathrm{mg} \mathrm{L}^{-1}$ of concentrated dye wastewater was used to carry out the degradation studies at room temperature.

From the obtained results, it was found that the degradation of BG dye has been increased with increase in the concentration of catalyst. This could be due to the generation of hydroxyl radical. The generation of hydroxyl radicals increases with an increase in catalyst dosage. About 99\% of BG dye was decolorized with the loading of $1 \mathrm{~g} \mathrm{~L}^{-1}$ of $\mathrm{TiO}_{2}$ over $90 \mathrm{~min}$ of operation. On increasing the catalyst dosage, the total active surface area escalates, that eventually tends to availability of additional active sites [19]. The other reason could be, on increasing the catalyst dosage, the collision frequency between the catalyst and dye increases. Few researchers did similar work and observed good results at higher catalyst dosage but the dye decolorization has decreased beyond $1 \mathrm{~g} \mathrm{~L}^{-1}$ catalyst loading. Concurrently, the increase in catalyst dosage may lead to an increase in turbidity. At higher turbidity, the passage of UV light into the solution diminishes and ultimately decreases the photoactivity $[20,21]$. The effect of catalyst loading on decolorization and percentage removal of dye is shown in Fig. 2.

\section{Effect of initial pH}

The experiments were carried out with $500 \mathrm{mg} \mathrm{L}^{-1}$ of BG dye, $1 \mathrm{~g} \mathrm{~L}^{-1} \mathrm{TiO}_{2}$ catalyst by varying the $\mathrm{pH}$ from 2 to 6 for $90 \mathrm{~min}$. The effect of $\mathrm{pH}$ on dye and organic pollutant removal was studied with the integrated system as shown in Fig. 3.

The required quantity of diluted $\mathrm{NaOH}$ and $\mathrm{H}_{2} \mathrm{SO}_{4}$ were used to adjust the $\mathrm{pH}$ of feed. The obtained results showed that the decolorization of BG dye at $\mathrm{pH} 2,4$ and 6 was 54, 99 and $84 \%$ respectively. From the results it is concluded that the $\mathrm{pH} 4$ is optimum to achieve efficient decolorization of BG dye in aqueous media. It was disclosed that the BG dye can endure in two ionic forms in water [22].

The BG dye (see supplemental information for its structure) is protonated at acidic $\mathrm{pH}$ to form a stable and colored form of a dye. Diversely, the BG dye gets deprotonated at alkaline $\mathrm{pH}$ to form a colorless leuco form, which is less stable [23]. Hence, in acidic medium, the oxidation of BG dye was effective. And the other reason is BG dye is a cationic dye and the $\mathrm{pH}$ of the solution decides its color intensity. From the previous work on Cibacron Brilliant Yellow 3G-P dye, it was observed that the degradation efficiency has been declined when the solution has become more acidic or more alkaline. Because of its amphoteric nature, the surface of the $\mathrm{TiO}_{2}$ catalyst is negatively charged and leads to electrostatic 


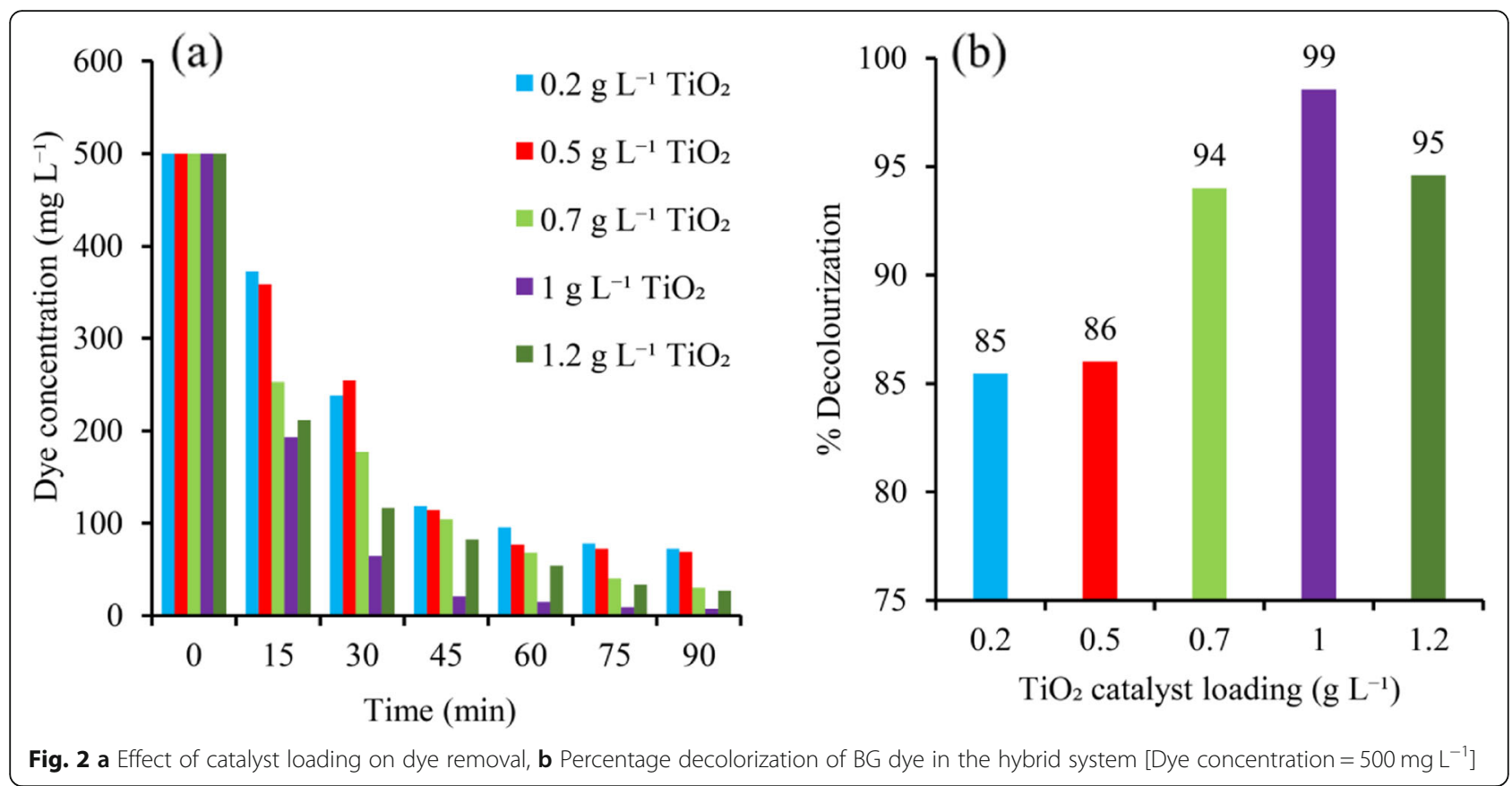

repulsion between the catalyst and the positively charged BG dye. This is one of the factors for BG degradation in the acidic medium [24].

\section{Effect of initial dye concentration}

PC coupled with NF was performed to study its performance for decolorizing BG dye by varying the initial dye concentration over the range of 250 to $1000 \mathrm{mg} \mathrm{L}^{-1}$. The observations from the experimental results are; as the concentration of BG dye in the stock solution increases, the decolorization of dye decreased. Figure 4 depicts dye decolorization at different initial BG dye concentrations. For efficient photocatalytic activity, free hydroxyl radicals are required. The generated hydroxyl radicals should be used immediately as their life span is very short. From the obtained results, when the initial dye concentration of the

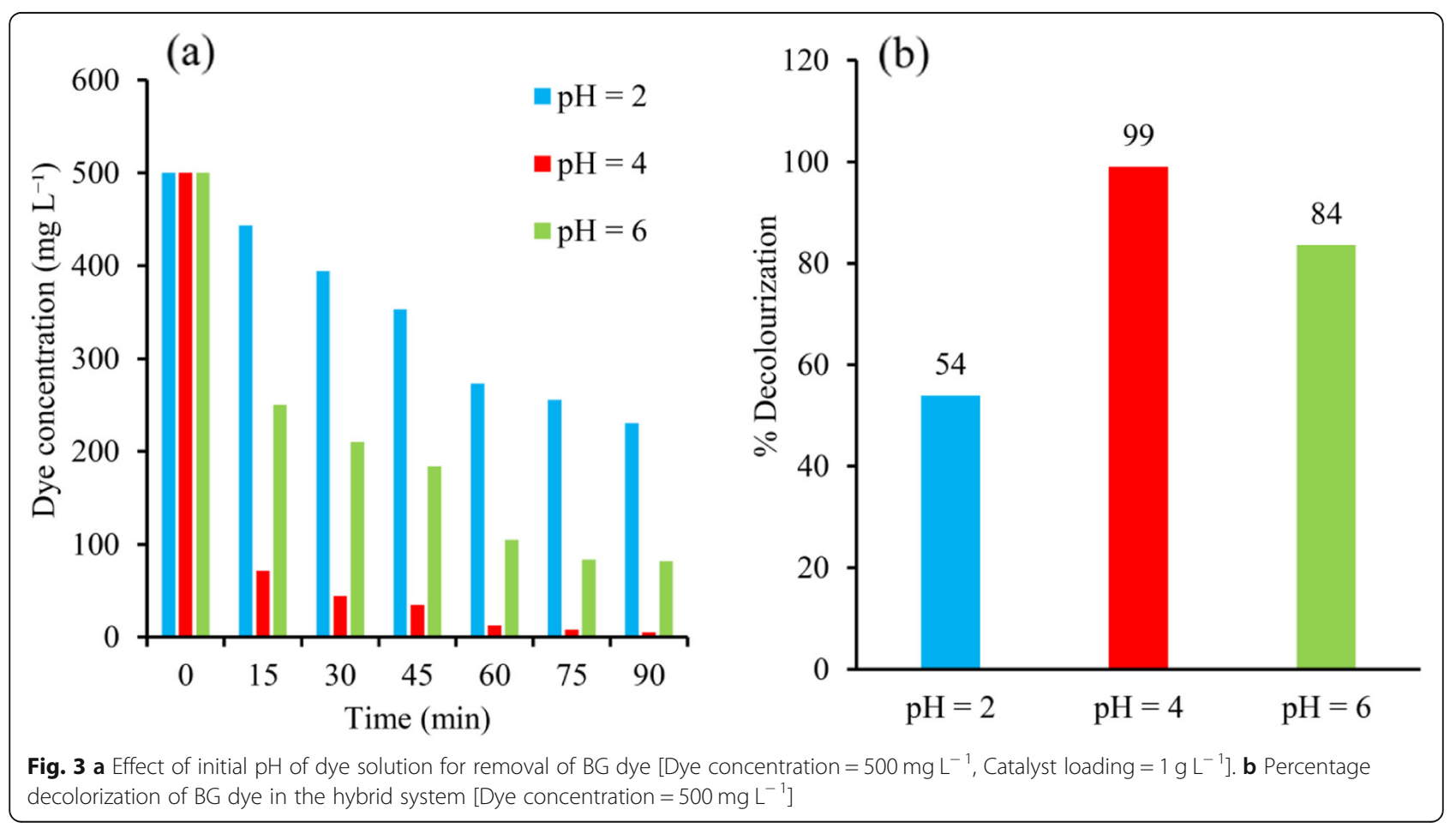




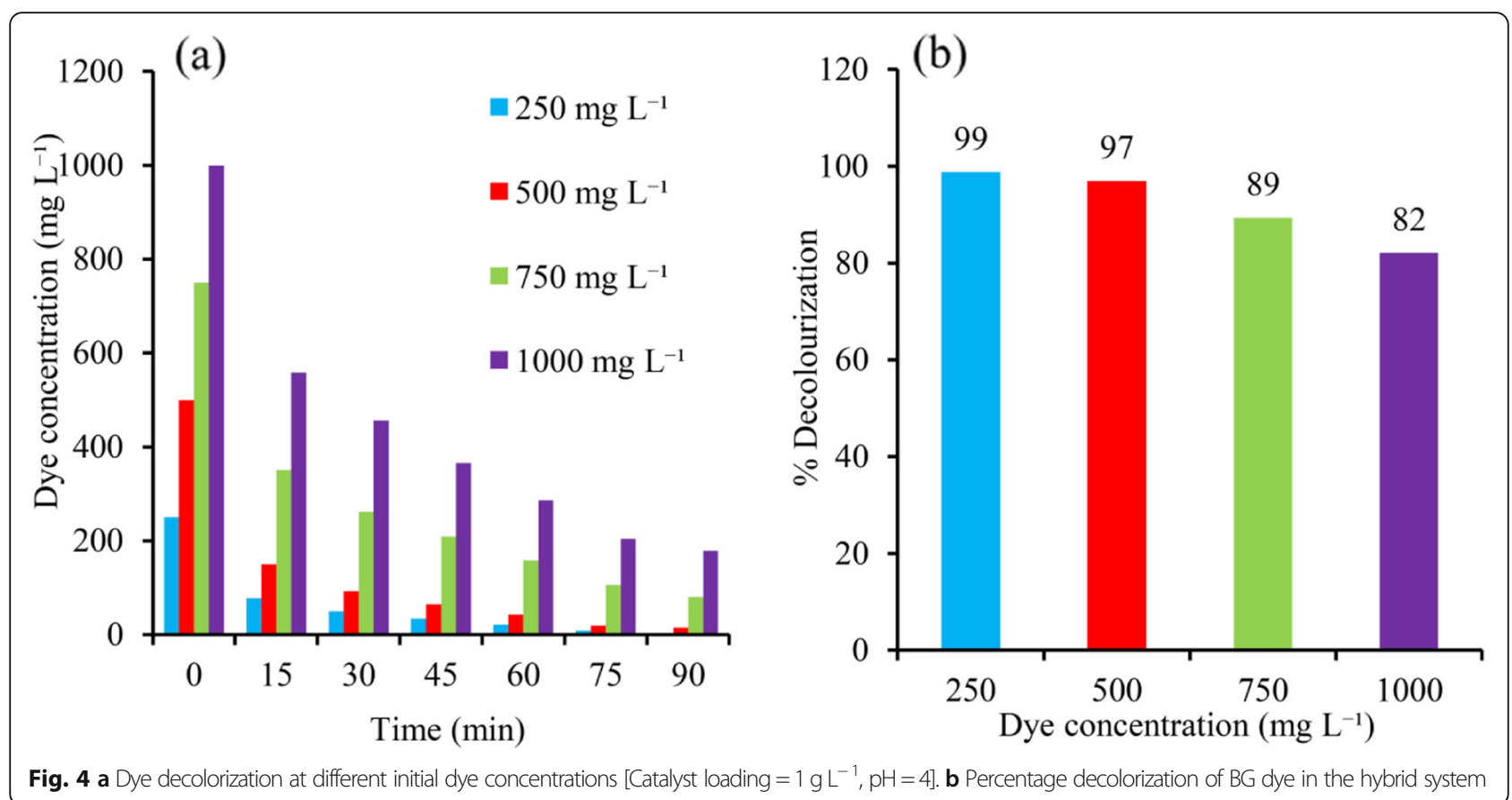

dye was escalated it occupied the catalyst surface and blocked the UV light transmission. The generated hydroxyl radicals were less when compared to the dye molecule concentration, that eventually led to a decrease in dye degradation. The other reasons possibly might be, the inorganic ions like nitrates and sulfates were generated on increasing the dye concentration which subsequently led to hinder dye degradation [25].
$\mathrm{TiO}_{2}$ loading effect on the permeate flux

Fluxes for the combination of feed solution of BG dye and $\mathrm{TiO}_{2}$ photocatalyst along with UV irradiation were investigated. The flux is almost constant in case of filtration in the presence of $\mathrm{TiO}_{2}$ alone or the combination of BG dye, $\mathrm{TiO}_{2}$ and UV irradiation. Lack of flux decline was observed, which could be due to the development of $\mathrm{TiO}_{2}$ cake layer on the membrane surface. However, no

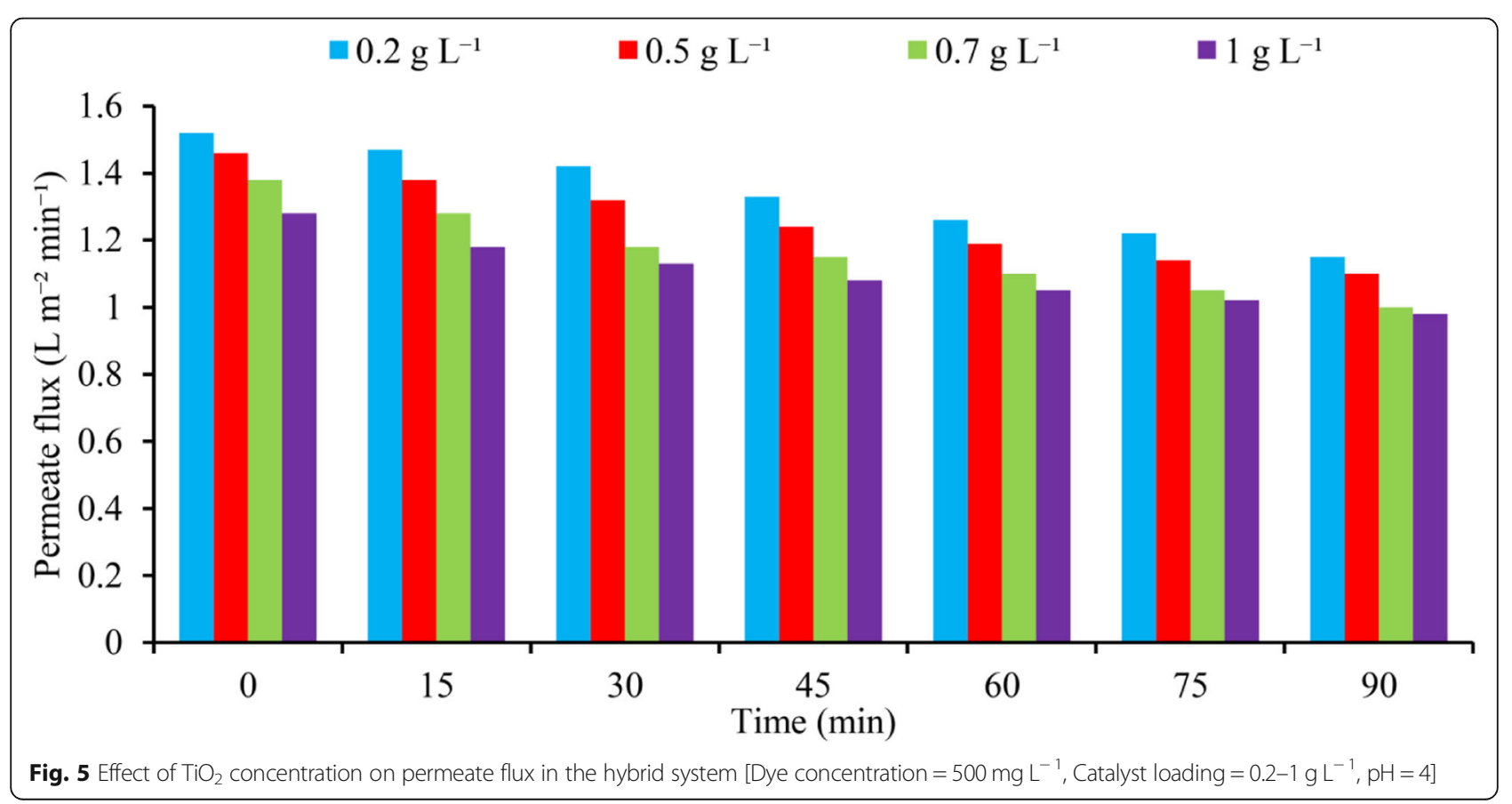


flux decline was observed in the case of filtration of BG dye alone and no irradiations of UV light in the above case has shown a little decline in the flux during $90 \mathrm{~min}$ of operation. Figure 5 explains the effect of $\mathrm{TiO}_{2}$ loading on the permeate flux at different $\mathrm{TiO}_{2}$ dosages $(0.2,0.5$, 0.7 and $\left.1 \mathrm{gL}^{-1}\right)$. The achieved results have shown that $\mathrm{TiO}_{2}$ dose applied in this study has exhibited a moderate effect on the permeate flux.

\section{Model development, regression analysis and optimization through RSM}

The test for the lack of fit and the linear regression coefficients are needed to be determined to acquire a well-fitted model. The outcome of the experimental design model has revealed that the predicted and the exploratory values were in good agreement. The collation of the forecasted and the experimental data could be contrasted with the

\section{(a)}

Design-Expert $\circledast$ Software \% BG Decolourization

Color points by value of \% BG Decolourization: 99.02

48.14

(b)

Design-Expert $₫$ Software \% BG Decolourization

Color points by value of \% BG Decolourization: 99.02

48.14
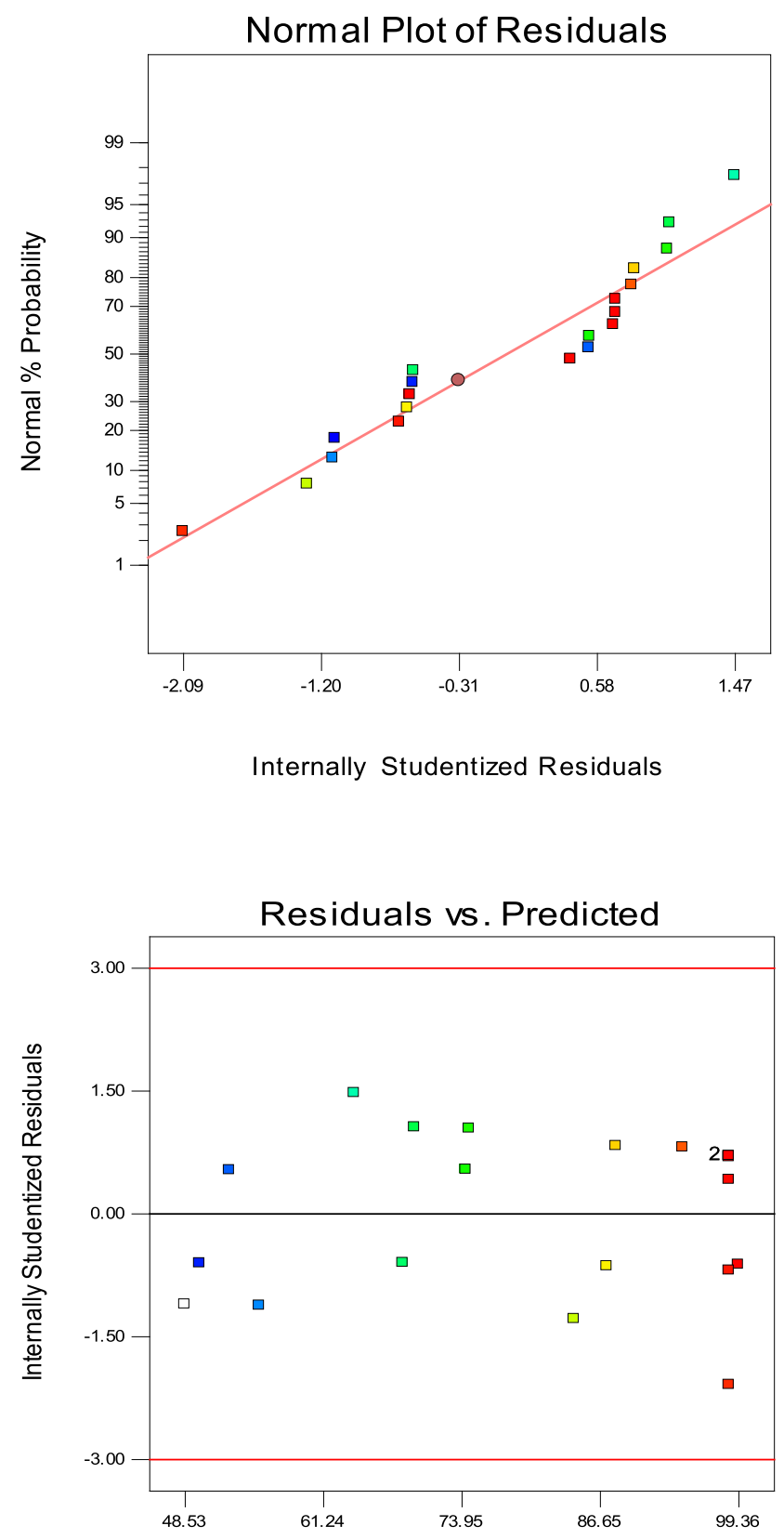

Fig. 6 a Normal plot of residuals, b Residuals vs. predicted 
obtained Eq. (2). From the experimental design model, the correlation coefficient $\left(R^{2}=0.9991\right)$ was found to be in strong agreement with the experimental values. And the Adjusted $R^{2}$ (Adj- $R^{2}=0.9983$ ) value was very near to that of the actual $R^{2}$ value and it was also in a good fit. Three factors CCD matrices were designed for this study. The terminal equation concerning the coded factors is given below.

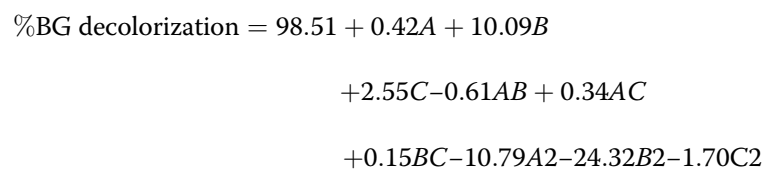

Figure $6 \mathrm{a}$ represents the residuals against the anticipated value. Feasible results can be observed in Fig. 6b. The ANOVA for the response surface quadratic model was performed and included in Table 3. By employing the F-test, the residual variance can be contrasted with the model variant. If Prob $>F$ value, then it is said to be momentous. The $F$ Value in this test is 1234 with a corresponding $p$-value of $<0.0001$ indicating $\mathrm{A}, \mathrm{B}$ and $\mathrm{C}$ are significant model parameters [26]. Besides $R^{2}$, the effectiveness of the models could also be analyzed using residuals. The normality of the residuals could be determined by using normal probability plots.

The purpose of this study is to generate the optimized input operating parameter values for the BG dye decolorization by using $\mathrm{PC}$ combined with the ceramic NF system. Experimental design models were used to optimize the input operating parameters. The desirable values of the process variables for the utmost decolorization ability were $1 \mathrm{~g} \mathrm{~L}^{-1}, \mathrm{pH} 4.2$, time $90 \mathrm{~min}$ for catalyst loading (A), $\mathrm{pH}(\mathrm{B})$ and Time $(\mathrm{C})$ respectively. At
Table 4 Optimized condition generated by the model, predicted \% BG decolorization and experimental \% BG decolorization

\begin{tabular}{lcccc}
\hline $\begin{array}{l}\text { Catalyst } \\
\text { loading }\end{array}$ & $\mathrm{pH}$ & Time & $\begin{array}{c}\text { Predicted \% BG } \\
\text { decolorization }\end{array}$ & $\begin{array}{l}\text { Experimental \% BG } \\
\text { decolorization }\end{array}$ \\
\hline 1 & 4.2 & 90 & 99.3 & 99 \\
\hline
\end{tabular}

these optimum values, the predicted and observed \% BG removals were close to $99 \%$ (Table 4).

Figures 7 and 8 explain the response surfaces, contours and the CCD matrix developed for the optimization of operating parameters for BG dye decolorization using combined PC and the NF system.

\section{Collation of various systems}

The individual and combined systems share similarities and differences. In order to understand those variations, various experiments were conducted on the individual and combined systems. Before proceeding to the experiments, an initial adsorption equilibrium study was conducted for $\mathrm{TiO}_{2}$ catalyst. One liter of BG dye solution was prepared in a beaker and $0.2 \mathrm{~g} \mathrm{~L}^{-1}$ of $\mathrm{TiO}_{2}$ powder was added to it. To exclude the apparent light illumination, the solution was put up on a magnetic stirrer in an unilluminated domain. The above procedure was carried on until the adsorption stability was attained. It was recognized that $0.2 \mathrm{~g} \mathrm{~L}^{-1}$ of $\mathrm{TiO}_{2}$ exhibited utmost adsorption of $11 \%$ BG dye onto the $\mathrm{TiO}_{2}$ surface and after $60 \mathrm{~min}, \mathrm{TiO}_{2}$ was reached to the equilibrium state. In this work, $1 \mathrm{~g} \mathrm{~L}^{-1}$ of catalyst loading, $\mathrm{pH} 4.2$ and time 90 min were identified as the optimum parameters and the effect of NF on dye decolorization was studied in these conditions.

Table 3 Analysis of variance (ANOVA) for response surface quadratic model [Partial sum of squares - Type III]

\begin{tabular}{llllll}
\hline Source & Sum of squares & df & Mean square & $F$ value & $p$-value prob. > F \\
\hline Model & 6574.93 & 9 & 730.55 & 1233.66 & $<0.0001$ \\
A - Catalyst loading & 1.74 & 1 & 1.74 & 2.94 & 0.1174 \\
B - pH & 1018.93 & 1 & 1018.93 & 1720.64 & $<0.0001$ \\
C - Time & 64.92 & 1 & 64.92 & 109.63 & $<0.0001$ \\
AB & 3.01 & 1 & 3.01 & 5.09 & 0.0477 \\
AC & 0.95 & 1 & 0.95 & 1.60 & 0.2351 \\
BC & 0.18 & 1 & 0.18 & 0.31 & 0.5905 \\
A $^{2}$ & 320.08 & 1 & 320.30 & 540.87 & $<0.0001$ \\
B $^{2}$ & 1626.01 & 1 & 1626.01 & 2745.80 & $<0.0001$ \\
C $^{2}$ & 7.02 & 1 & 7.92 & 13.38 & 0.0044 \\
Residual & 5.92 & 10 & 0.59 & & \\
Lack of fit & 2.54 & 5 & 0.51 & 0.75 & 0.6201 \\
Pure error & 3.38 & 5 & 0.68 & & Not significant \\
Cor total & 6580.86 & 19 & & & \\
\hline
\end{tabular}




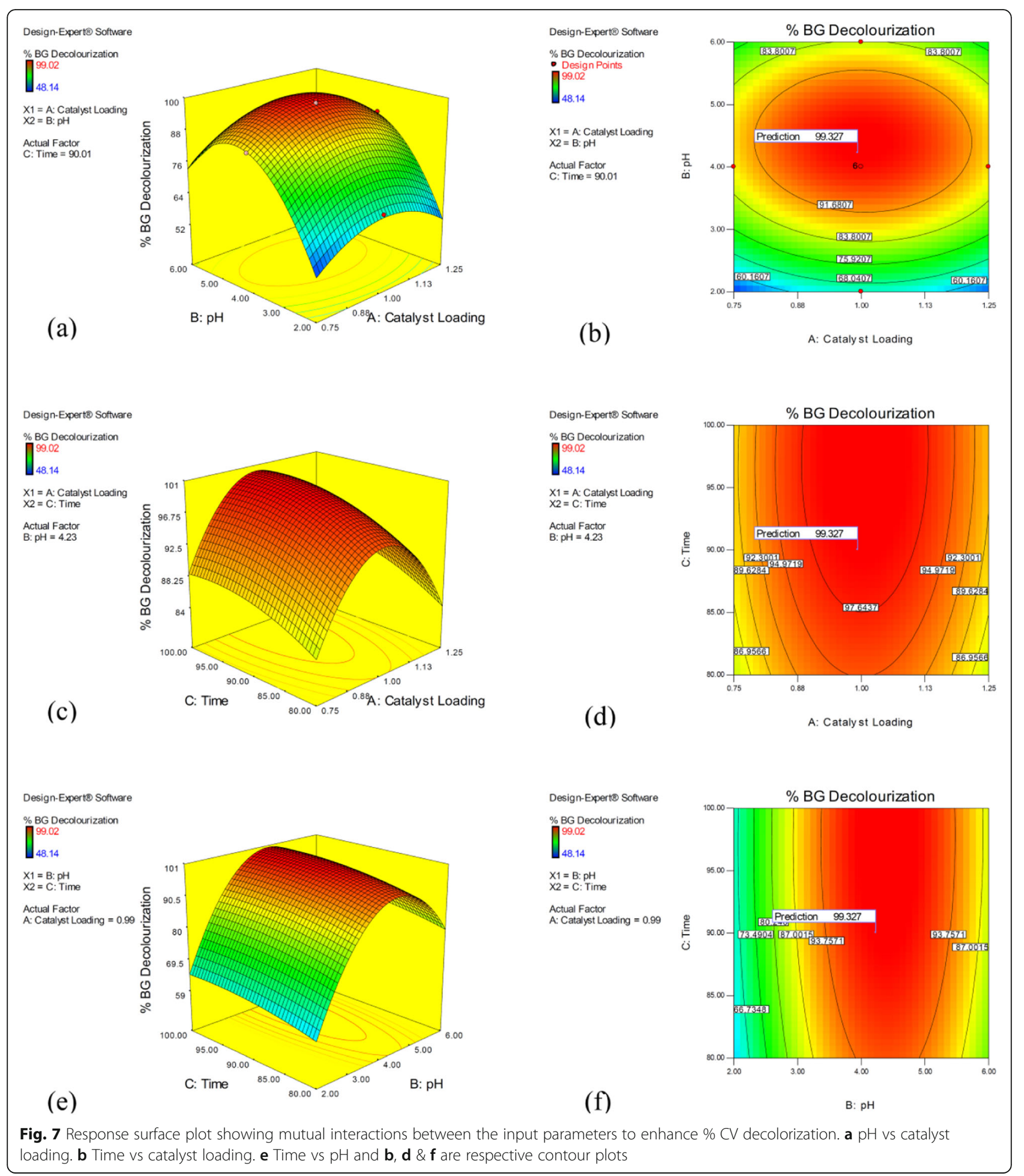

The performance of process integration of ceramic NF membrane and $\mathrm{PC}$ on dye reclamation was also investigated at the ideal working parameters like $1 \mathrm{~g} \mathrm{~L}^{-1}$ of $\mathrm{TiO}_{2}$ dosage and $\mathrm{pH}=4.2$. Over $90 \mathrm{~min}$ of operation, $99 \%$ of dye decolorization was obtained with the combined system. From the results, it can be concluded that the synergistic effect of the combined process was improved compared to the individual systems. Figure 9 illustrates the performance of various systems on dye removal.

In addition to the dye decolorization, the dye degradation was analyzed at optimum operating parameters of catalyst loading $1 \mathrm{~g} \mathrm{~L}^{-1}, \mathrm{pH} 4.2$ and $90 \mathrm{~min}$ and observed $90 \%$ of 


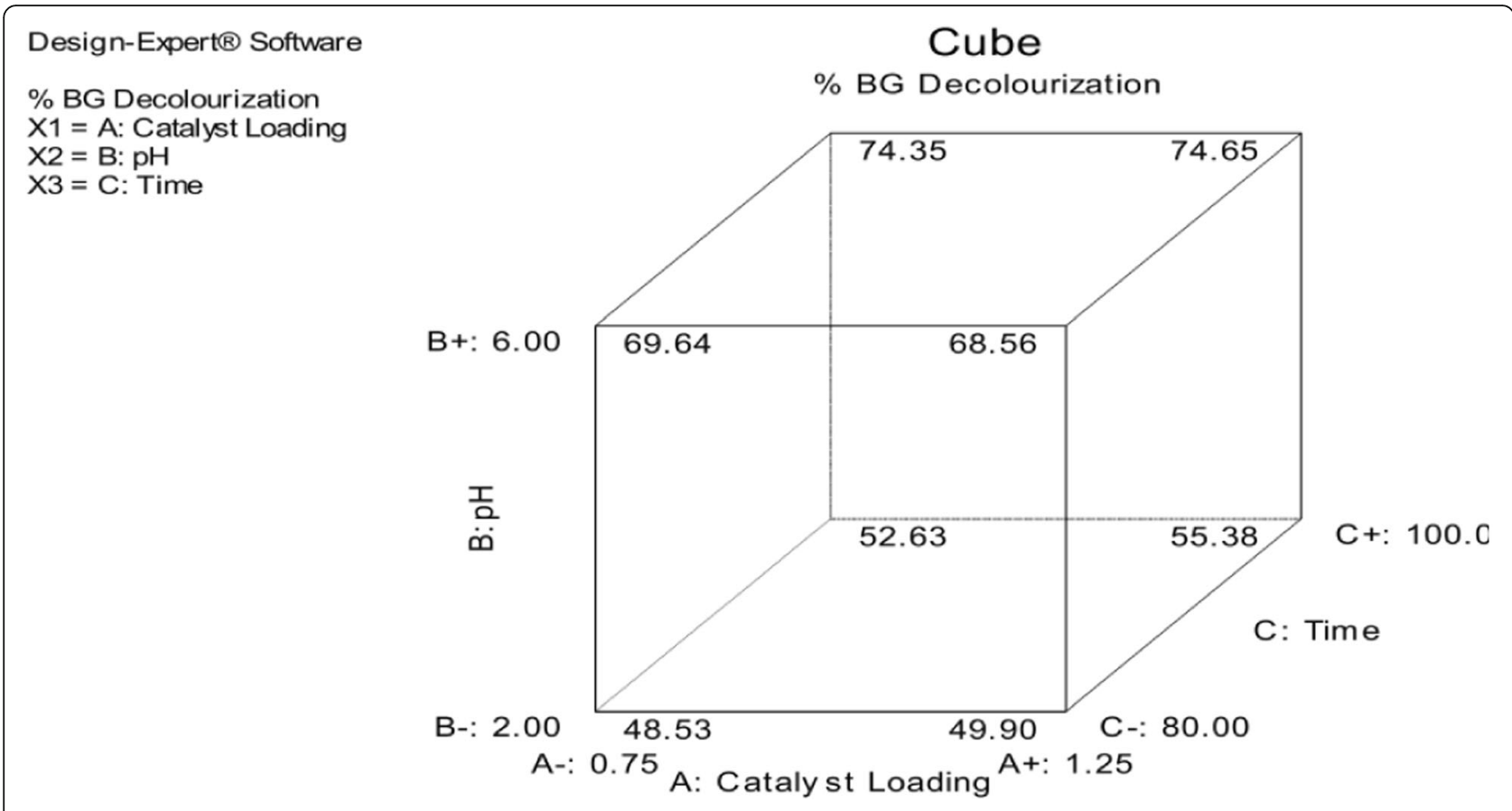

Fig. 8 CCD Matrix

TOC removal. Figure 10 show the percentage removal of TOC in various systems.

\section{Reuse of $\mathrm{TiO}_{2}$ photocatalyst}

Reusing the $\mathrm{TiO}_{2}$, experiments were conducted for two repeated cycles. In the first cycle experiment it was carried out for $90 \mathrm{~min}$ at $1 \mathrm{~g} \mathrm{~L}^{-1}$ of catalyst loading, 500 mg dye concentration and $\mathrm{pH} 4.2$ and observed $62 \%$ of dye decolorization (Fig. 11). Subsequent cycles of operation show a decline in the percentage decolorization of BG dye to $56 \%$. This decrease in the efficiency of the system might be because of the lack of possibility of active
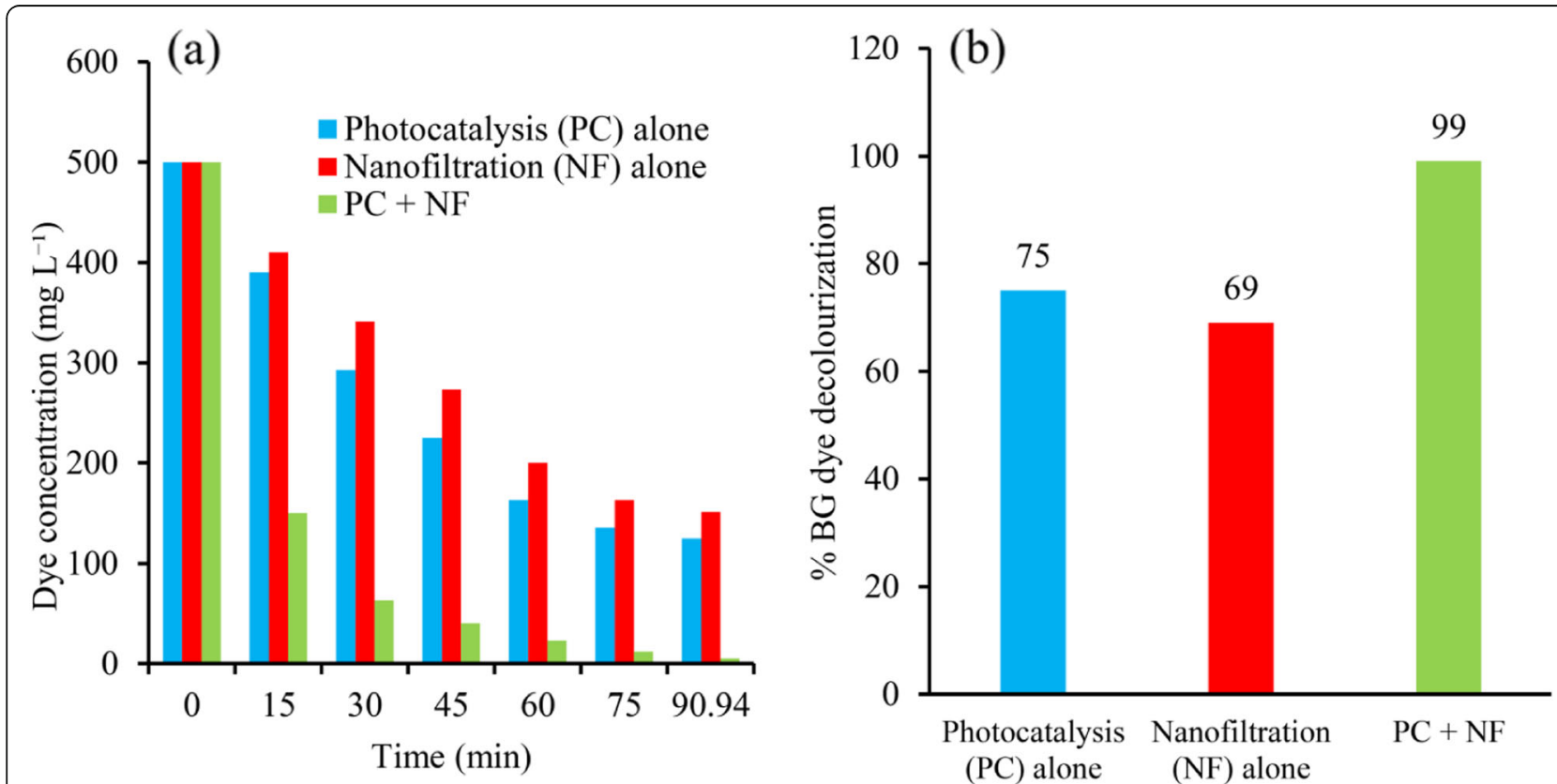

Fig. 9 a Dye decolorization performance in various systems [Dye concentration $=500 \mathrm{mg} \mathrm{L}^{-1}$, Catalyst loading $=1 \mathrm{~g} \mathrm{~L}^{-1}, \mathrm{pH}=4.2, \mathrm{Time}=90 \mathrm{~min}$ ]. b Decolorization Percentage of BG dye in various systems [Dye concentration $=500 \mathrm{mg} \mathrm{L}^{-1}$, Catalyst loading $=1 \mathrm{~g} \mathrm{~L}^{-1}, \mathrm{pH}=4.2$, Time $=90 \mathrm{~min}$ ] 


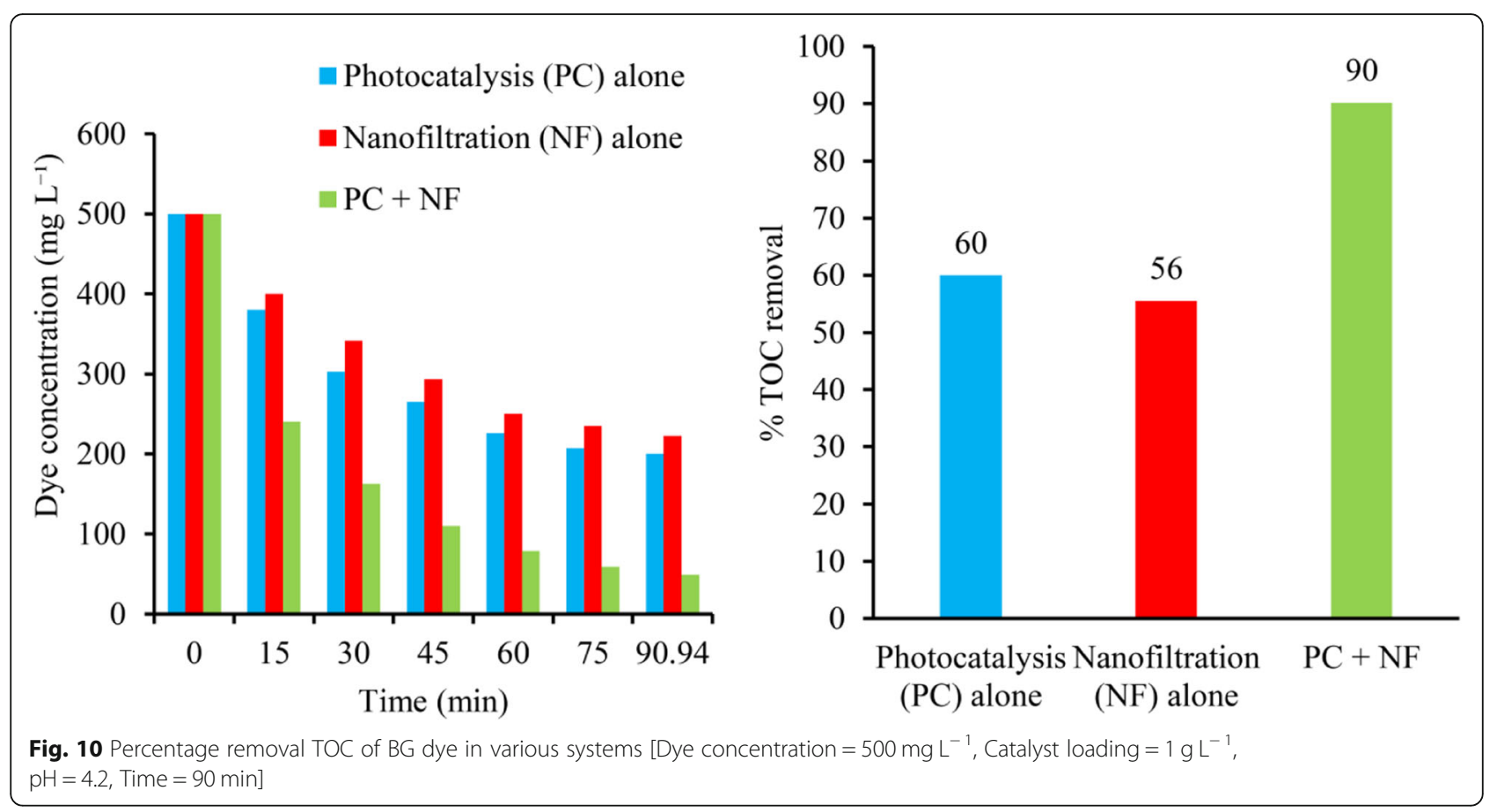

sites on the $\mathrm{TiO}_{2}$ particle. This is due to some of the active sites occupied with dye compounds. FernandezIbanez et al. [27] have worked on the retrieval and reuse of the $\mathrm{TiO}_{2}$ particles in solar PC by employing colloidal stability. In their research work, the electrolyte coagulation and charge neutralisation processes were employed to increase the catalyst recovery. From the results, it was observed that at isoelectric point, the hydrodynamic diameter and settling rates of $\mathrm{TiO}_{2}$ particles are highest and it was also found that at various $\mathrm{pH}$ values the suspensions are substantial. For the treatment of tetrachloroethylene $\left(\mathrm{C}_{2} \mathrm{Cl}_{4}\right)$ [27], $\mathrm{TiO}_{2}$ was reused in solar PC pilot-plant. It was observed that the reuse of water and catalyst without segregation has aggravated the photocatalytic efficiency, but photocatalyst is not deactivated when $\mathrm{TiO}_{2}$ is detached. This research has revealed that excluding a small quantity, $97 \%$ of the $\mathrm{TiO}_{2}$ particles could be reused. Subramonian et al. [28] treated the paper and pulp industry effluent by employing the $\mathrm{Fe}_{2} \mathrm{O}_{3}-\mathrm{TiO}_{2}$ photocatalyst. Also, the $\mathrm{Fe}_{2} \mathrm{O}_{3}-\mathrm{TiO}_{2}$ photocatalyst recovery and reuse were also studied by using sedimentation and applied magnetic field. In their

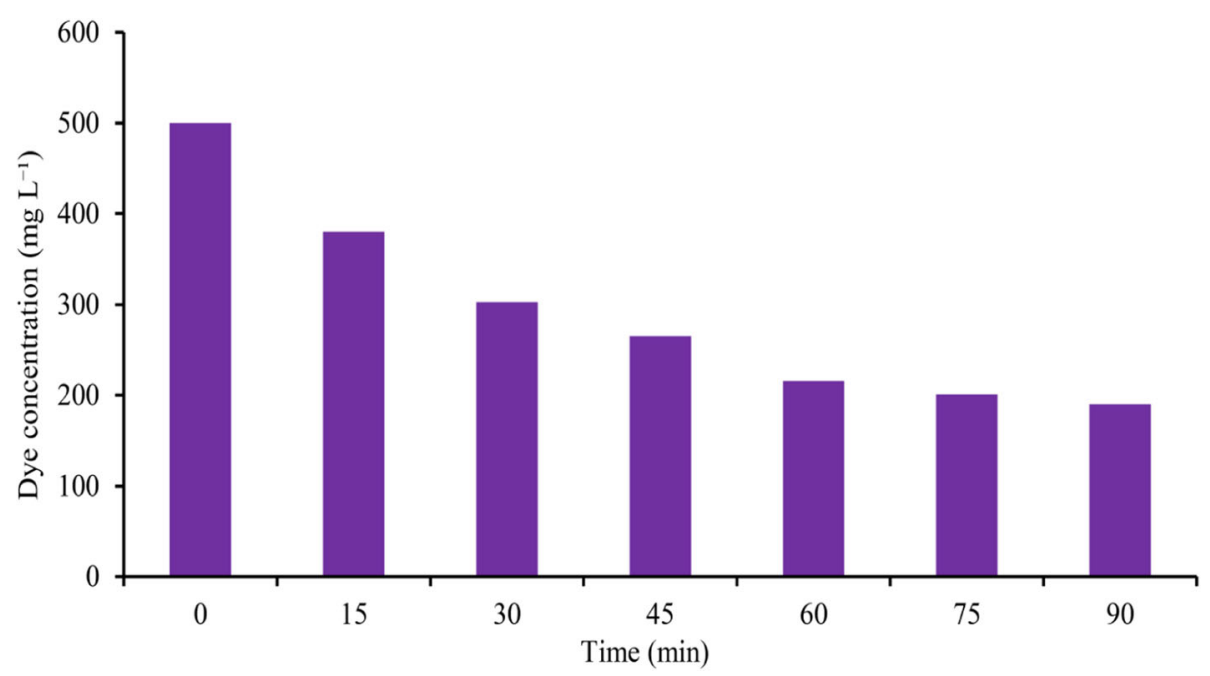

Fig. 11 Dye decolorization by reusing $\mathrm{TiO}_{2}$ (first cycle experiment) catalyst [Dye concentration $=500 \mathrm{mg} \mathrm{L}^{-1}$, Catalyst loading $=1 \mathrm{~g} \mathrm{~L}^{-1}$, $\mathrm{pH}=4.2$, Time $=90 \mathrm{~min}]$ 
experimental study, at certain photocatalytic constraint, the $\mathrm{Fe}_{2} \mathrm{O}_{3}-\mathrm{TiO}_{2}$ photocatalyst was reused for several cycles. In the first cycle a very little change in chemical oxygen demand removal was observed (3.7\% difference). Good chemical stability was shown by the reused photocatalyst without any decline in photoactivity from first to fifth cycle. $\mathrm{Fe}_{2} \mathrm{O}_{3}-\mathrm{TiO}_{2}$ retrieval was useful for reducing environmental pollution and minimizing the inclusive cost. Easy separation and maximum reusability of $\mathrm{Fe}_{2} \mathrm{O}_{3}-\mathrm{TiO}_{2}$ from the wastewater using magnetic field were demonstrated in this work. Salaeh et al. [29] investigated the photocatalyst reactivation for wastewater treatment by employing chemical and thermal methods. Under simulated solar irradiation, the diclofenac (DCF) was removed using a photocatalyst prepared from ironexchange zeolite and titania. From the experimental results it was observed that the maximum TOC and DCF were removed by thermal reactivation method than the chemical method. However, the biodegradability and stability of the photocatalyst in reuse cycles were ameliorated slightly by the chemical reactivation method.

\section{Conclusions}

The BG dye decolorization and degradation by the combined PC and NF was strongly influenced by the operating conditions such as catalyst loading, initial $\mathrm{pH}$ and time. The integrated system was found to be effective for the BG dye removal in the presence of $\mathrm{TiO}_{2}$. This operation has ensured efficient separation of the catalyst from the treated wastewater for further reuse of $\mathrm{TiO}_{2}$. At $\mathrm{pH} 4.2$, catalyst loading of $1 \mathrm{~g} \mathrm{~L}^{-1}$ and $90 \mathrm{~min}$ duration time, the dye removal was observed to be maximum. These operating parameters were optimized using the RSM experimental design model. These parameters were considered as the optimum parameters for the decolorization of BG dye. In the integrated system, from the acquired outcomes it was observed that $99 \%$ of dye and $90 \%$ of TOC was removed after $90 \mathrm{~min}$ of operation at $\mathrm{pH} 4.2$ and $1 \mathrm{~g} \mathrm{~L}^{-1}$ of $\mathrm{TiO}_{2}$ loading.

\section{Supplementary information}

Supplementary information accompanies this paper at https://doi.org/10. 1186/s42834-020-00050-y.

Additional file 1. Chemical structure of BG dye.

\section{Acknowledgements}

The authors wish to thank the Director, NIT Warangal and the MHRD, India for supporting this research work.

\section{Authors' contributions}

NYD has collected the data related to the research, designed and performed the experiments and wrote the paper. AKK has conceived and designed the analysis, contributed to RSM and corrected the manuscript. DS has guided the current research work and corrected the manuscript. The author(s) read and approved the final manuscript.

\section{Funding}

This research work was financially supported by NIT Warangal (an institute under MHRD), India.

\section{Availability of data and materials}

All data generated or analyzed during this study are included in this published article.

\section{Competing interests}

The authors declare that they have no known competing financial interests or personal relationships that could have appeared to influence the work reported in this paper.

Received: 18 July 2019 Accepted: 16 April 2020

Published online: 12 May 2020

\section{References}

1. Tay JH, Chen D, Sun DD. Removal of color substances using photocatalytic oxidation for membrane filtration processes. Water Sci Technol. 2001;43: 319-25.

2. Li XZ, Fan CM, Sun YP. Enhancement of photocatalytic oxidation of humic acid in $\mathrm{TiO}_{2}$ suspensions by increasing cation strength. Chemosphere. 2002; 48:453-60.

3. Bruschweiler BJ, Kung S, Burgi D, Muralt L, Nyfeler E. Identification of nonregulated aromatic amines of toxicological concern which can be cleaved from azo dyes used in clothing textiles. Regul Toxicol Pharmacol. 2014;69: 263-72.

4. Rawat D, Mishra V, Sharma RS. Detoxification of azo dyes in the context of environmental processes. Chemosphere. 2016;155:591-605.

5. Platzek T, Lang C, Grohmann G, Gi US, Baltes W. Formation of a carcinogenic aromatic amine from an azo dye by human skin bacteria in vitro. Hum Exp Toxicol. 1999;18:552-9.

6. Stingley RL, Zou W, Heinze TM, Chen HZ, Cerniglia CE. Metabolism of azo dyes by human skin microbiota. J Med Microbiol. 2010;59:108-14.

7. Bruschweiler BJ, Merlot C. Azo dyes in clothing textiles can be cleaved into a series of mutagenic aromatic amines which are not regulated yet. Regul Toxicol Pharmacol. 2017:88:214-26.

8. Kagaya S, Shimizu K, Arai R, Hasegawa K. Separation of titanium dioxide photocatalyst in its aqueous suspensions by coagulation with basic aluminium chloride. Water Res. 1999;33:1753-5.

9. China SS, Chiang K, Fane AG. The stability of polymeric membranes in a $\mathrm{TiO}_{2}$ photocatalysis process. J Membr Sci. 2006;275:202-11.

10. Mozia S. Photocatalytic membrane reactors (PMRs) in water and wastewater treatment. A review. Sep Purif Technol. 2010;73:71-91.

11. Fang H, Sun DD, Wu M, Phay W, Tay JH. Removal of humic acid foulant from ultrafiltration membrane surface using photocatalytic oxidation process. Water Sci Technol. 2005:51:373-80.

12. Lee $\mathrm{SA}$, Choo KH, Lee $\mathrm{CH}$, Lee HI, Hyeon T, Choi W, et al. Use of ultrafiltration membranes for the separation of $\mathrm{TiO}_{2}$ photocatalysts in drinking water treatment. Ind Eng Chem Res. 2001;40:1712-9.

13. Wharton SJ, Basu SP, Ashe HL. Smad affinity can direct distinct readouts of the embryonic extracellular Dpp gradient in Drosophila. Curr Biol. 2004;14: 1550-8

14. Zhao YJ, Zhong J, Li H, Xu NP, Shi J. Fouling and regeneration of ceramic microfiltration membranes in processing acid wastewater containing fine $\mathrm{TiO}_{2}$ particles. J Membr Sci. 2002;208:331-41.

15. Muthukumaran S, Nguyen DA, Baskaran K. Performance evaluation of different ultrafiltration membranes for the reclamation and reuse of secondary effluent. Desalination. 2011;279:383-9.

16. Bashir MJK, Amr SSA, Aziz SQ, Aun NC, Sethupathi S. Wastewater treatment processes optimization using response surface methodology (RSM) compared with conventional methods: review and comparative study. Middle-East J Sci Res. 2015:23:244-52.

17. Mane VS, Mall ID, Srivastava VC. Use of bagasse fly ash as an adsorbent for the removal of brilliant green dye from aqueous solution. Dyes Pigments. 2007;73:269-78.

18. Ahmadi M, Vahabzadeh F, Bonakdarpour B, Mofarrah E, Mehranian M. Application of the central composite design and response surface methodology to the advanced treatment of olive oil processing wastewater using Fenton's peroxidation. J Hazard Mater. 2005;123:187-95. 
19. Behnajady MA, Modirshahla N, Hamzavi R. Kinetic study on photocatalytic degradation of C.I. acid yellow 23 by ZnO photocatalyst. J Hazard Mater. 2006;133:226-32.

20. Kabsch-Korbutowicz M, Biłyk A, Mołczan M. The effect of feed water pretreatment on ultrafiltration membrane performance. Pol J Environ Stud. 2006;15:719-25.

21. Kim J, Davies SHR, Baumann MJ, Tarabara W, Masten SJ. Effect of ozone dosage and hydrodynamic conditions on the permeate flux in a hybrid ozonation-ceramic ultrafiltration system treating natural waters. J Membr Sci. 2008;311:165-72.

22. Mitrowska K, Posyniak A, Zmudzki J. Determination of malachite green and leucomalachite green residues in water using liquid chromatography with visible and fluorescence detection and confirmation by tandem mass spectrometry. J Chromatogr A. 2008;1207:94-100.

23. Neppolian B, Choi HC, Sakthivel S, Arabindoo B, Murugesan V. Solar light induced and $\mathrm{TiO}_{2}$ assisted degradation of textile dye reactive blue 4 . Chemosphere. 2002:46:1173-81.

24. Kumar R, Barakat MA. Decolourization of hazardous brilliant green from aqueous solution using binary oxidized cactus fruit peel. Chem Eng J. 2013; 226:377-83.

25. Rauf MA, Meetani MA, Hisaindee S. An overview on the photocatalytic degradation of azo dyes in the presence of $\mathrm{TiO}_{2}$ doped with selective transition metals. Desalination. 2011;276:13-27.

26. Zhu ZZ, Jiang T, He JH, Barba FJ, Cravotto G, Koubaa M. Ultrasound-assisted extraction, centrifugation and ultrafiltration: multistage process for polyphenol recovery from purple sweet potatoes. Molecules. 2016;21:1584

27. Fernandez-Ibanez P, Blanco J, Malato S, de las Nieves FJ. Application of the colloidal stability of $\mathrm{TiO}_{2}$ particles for recovery and reuse in solar photocatalysis. Water Res. 2003;37:3180-8.

28. Subramonian W, Wu TY, Chai SP. Photocatalytic degradation of industrial pulp and paper mill effluent using synthesized magnetic $\mathrm{Fe}_{2} \mathrm{O}_{3}-\mathrm{TiO}_{2}$ : treatment efficiency and characterizations of reused photocatalyst. J Environ Manag. 2017;187:298-310.

29. Salaeh S, Kovacic M, Kosir D, Kusic H, Stangar UL, Dionysiou DD, et al. Reuse of $\mathrm{TiO}_{2}$-based catalyst for solar driven water treatment; thermal and chemical reactivation. J Photoch Photobio A. 2017;333:117-29.

\section{Publisher's Note}

Springer Nature remains neutral with regard to jurisdictional claims in published maps and institutional affiliations.

Ready to submit your research? Choose BMC and benefit from:

- fast, convenient online submission

- thorough peer review by experienced researchers in your field

- rapid publication on acceptance

- support for research data, including large and complex data types

- gold Open Access which fosters wider collaboration and increased citations

- maximum visibility for your research: over $100 \mathrm{M}$ website views per year

At $\mathrm{BMC}$, research is always in progress.

Learn more biomedcentral.com/submissions 